NISTIR 7615

\title{
Gypsum Stairwell Enclosure Wall System Tests under Uniform Static Pressure
}





\title{
Gypsum Stairwell Enclosure Wall System Tests under Uniform Static Pressure
}

\author{
H.S. Lew \\ Building and Fire Research Laboratory
}

July 2009

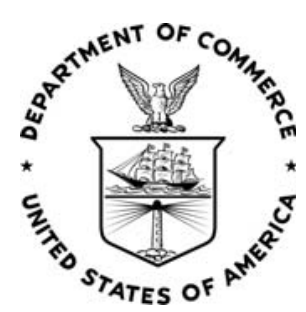

U.S. Department of Commerce Gary Locke, Secretary

National Institute of Standards and Technology

Patrick D. Gallagher, Deputy Director 
The policy of the National Institute of Standards and Technology is to use The International System of Units in its published materials. Because this report is intended for the U.S. building construction industry which uses inch-pound units, it is more practical and less confusing to use inch-pound units rather than metric units within quoted text. 


\section{Abstract}

The importance of the structural integrity of the exit stairway enclosures was clearly shown by the collapse of the World Trade Center Towers. The investigation report of the National Institute of Standards and Technology recommended that the design, functional integrity, and survivability of the egress and other life safety systems should be enhanced by considering accidental structural loads. Following this recommendation, the Ad Hoc Committee on Terrorism Resistant Buildings (TRB) of the International Code Council (ICC) advocated a code change proposal on the structural integrity of exit stairway enclosures during the 2007-2008 code development cycle of the International Building Code (IBC). The proposal required that for all buildings more than $420 \mathrm{ft}$ in height, the exit stairway enclosure wall surface should be capable of resisting a uniform static pressure of not less than 2 psi applied perpendicular to the exterior of the enclosure. This report presents results of three two-hour fire rated gypsum stairway

enclosure assemblies, which are commonly used in high-rise construction, subjected to a uniform static pressure applied to the surface.

Key Words: Enclosure; gypsum; stairwell; tests; walls. 


\section{Acknowledgements}

The experimental program reported herein was performed as a joint effort of a number of individuals within the Structures Group of the Building and Fire Research Laboratory. Specifically, the contributions of Frank Davis, who meticulously prepared test specimens and assembled the test setup, Dr. Long T. Phan, who supported the data acquisition and evaluation, and Dr. John L. Gross, who captured photographic images of the tests, are gratefully acknowledged. Comments and suggestions of Mr. Gary Lewis, Chair of the ICC's Ad Hoc Committee on Terrorism Resistant Buildings, are greatly appreciated. 
[Type text]

\section{Table of Contents}

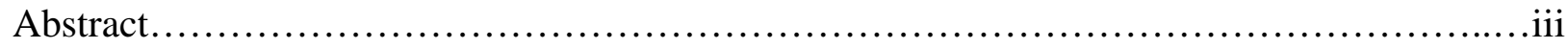

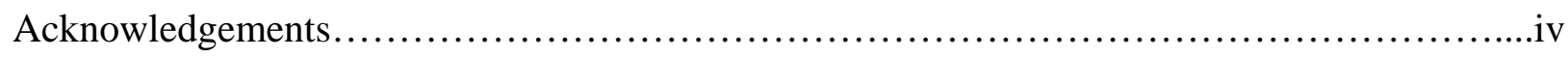

Table of Contents.........................................................................

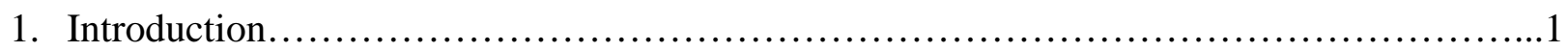

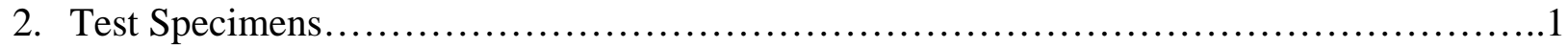

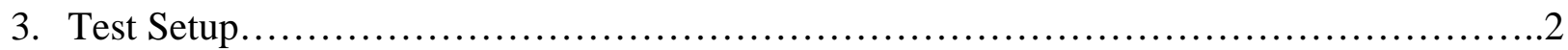

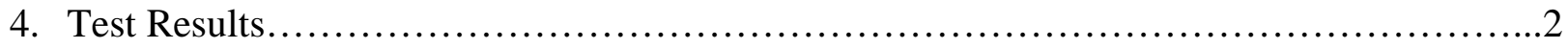

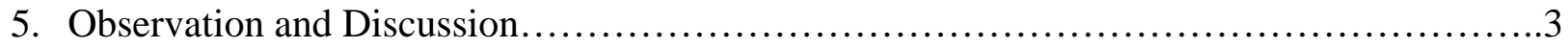





\section{Introduction}

The investigation of the collapse of the World Trade Center Towers by the National Institute of Standards and Technology (NIST) concluded that the integrity of stairway enclosures in multistory buildings is important in assuring safe evacuation of occupants ${ }^{1}$. The investigation report recommended that "the design, functional integrity, and survivability of the egress and other life safety systems (e.g., stairwell and elevator shafts and active fire protection systems) should be enhanced by considering accidental structural loads such as those induced by overpressures (e.g., gas explosions), impacts, or major hurricanes and earthquakes, in addition to fire separation requirements." Following this recommendation, the Ad Hoc Committee on Terrorism Resistant Buildings Committee (TRB) of the International Code Council (ICC) advocated a code change proposal on the structural integrity of exit stairway enclosures during the 2007-2008 code development cycle of the International Building Code (IBC). The proposal required that for all buildings more than $420 \mathrm{ft}$ in height, exit stairway enclosure wall surfaces, from the top of the floor to the underside of the floor above or roof supporting members, should be capable of resisting a uniform static pressure of not less than 2 psi applied perpendicular to the exterior of the enclosure. At the March 2008 ICC code development hearings, questions were raised whether conventional stairway enclosure systems would meet this requirement.

To examine the ability of conventional light-weight stairway enclosure systems commonly used in high-rise construction to meet the proposed 2 psi requirement, NIST's Building and Fire Research Laboratory carried out three tests of gypsum stairway enclosure systems under static uniform pressure.

\section{Test Specimens}

A total of three specimens were tested. The test specimens consisted of gypsum shaft wall assemblies having a two-hour fire rating. The test wall sections were 72-in wide and 100-in high. They were fabricated by NIST using materials purchased from a local building material supplier. Two types of specimens were constructed: one with 2-1/2 in steel C-H studs (20 ga.) and the other with 4 inch steel C-H studs (20 ga.). Figure 1 shows the cross section of C-H studs. The studs were spaced at 24 in on center. For both types, two layers of 1/2-in Type-X gypsum panels were applied either vertically or horizontally to the C-H studs with screws (See Table 1), and 1in "gypsum liner panels" were inserted into the grooves of the $\mathrm{C}-\mathrm{H}$ studs. Along the exterior edges of the panel, the liner panels were fastened to the $\mathrm{C}-\mathrm{H}$ studs with screws at 12 in on center. The assembled gypsum panel was placed between top and bottom steel J-runners (20 ga.). The ends of the C-H studs were fastened to both flanges of the J-runners with screws. Both the top and bottom J-runners were fastened to 6-inch x 6-inch hardwood members with screws. The wood members were in turn bolted to the steel reaction beams. The top reaction beam was attached to a concrete reaction wall with 1-1/2 in diameter post-tensioning bolts, and the bottom reaction beam was anchored to the laboratory floor. Thus, the specimen acted as a one-way plate

\footnotetext{
${ }^{1}$ NIST NCSTAR 1, Final Report on the Collapse of the World Trade Center Towers, National Institute of Standards and Technology, Gaithersburg, MD, September 2005
} 
supported at the top and bottom for a span of 100 in. A specimen placed in the test fixture is shown in Figure 2.

Table 1 Specimen Description

\begin{tabular}{|c|c|c|}
\hline Specimen & Stud Type & Panel Orientation \\
\hline 1 & $2-1 / 2$ in. C-H & Vertical \\
\hline 2 & 4 in. C-H & Vertical \\
\hline 3 & 4 in. C-H & Horizontal \\
\hline
\end{tabular}

\section{Test Setup}

The test section was loaded over the entire surface by an air bag. The air bag was placed between the test specimen and the concrete reaction wall. In all tests, the pressure was applied to the gypsum panel side. Thus, the gypsum panels were in compression while the liner panels were in tension.

The air pressure in the bag was increased at a rate of $0.15 \mathrm{psi} / \mathrm{min}$ until the test panel could no longer sustain the pressure increase as indicated by a large increase in deflection at the center of the panel. To monitor any horizontal movement of the J runners during test, a dial gage was positioned against the flange of the J-runners (see Figure 2). An LVDT ${ }^{2}$ (linear variable differential transformer) was placed at the geometric center of the test panel to measure the displacement response of the test specimen to the applied pressure.

The air pressure in the bag was measured by a digital transducer ${ }^{3}$. The data from the transducer and LVDT were recorded by a digital data acquisition system capable of sampling at a rate of 2 KHz. However, a sampling rate of $5 \mathrm{~Hz}$ was used for the tests since they were essentially static load tests. The recorded data were saved to the computer disk for data processing.

\section{Test Results}

\section{Specimen 1 (2-1/2 in C-H Stud)}

This specimen had the gypsum panels applied in the vertical direction. When buckling of the compression side of the stud occurred, a large increase in the lateral deflection at the mid height of the panel was noted. The deflection increased rapidly as the pressure in the air bag increased. The testing was stopped at about $2.1 \mathrm{psi}$. The post-test photograph of this specimen is shown in Figure 3. It is seen that buckling of the C-H stud and cracking in the gypsum liner panels on the tension side developed at the mid height of the test panel. Removal of the gypsum panels

\footnotetext{
${ }^{2}$ LVDT used has \pm 0.001 in. resolution.

${ }^{3}$ The digital transducer has \pm 0.01 psi resolution.
} 
revealed that local buckling of the compression flange developed in all four C-H studs (Similar to Figure 11).

Figure 4 shows a plot of the air-bag pressure vs. the panel center deflection for Specimen 1 . It is seen that the panel behaved essentially elastically up to about 1.4 psi. Buckling of the compression flange developed at this pressure level and the deflection at the center of the panel increased rapidly.

\section{Specimen 2 (4 in. C-H Stud)}

This specimen had the gypsum panels applied in the vertical direction. The post-test photograph of this specimen is shown in Figure 5, and a close up view of the buckling of the C-H stud is shown in Figure 6. The plot of the air-bag pressure vs. the panel center deflection is shown in Figure 7. At about 2 psi, the compression flange began to buckle. Buckling of the web also appeared at about 2.4 psi, and cracks developed on the tension side of the gypsum liner panels. After reaching 3 psi the panel center deflection increased rapidly (see Figure 7). When the specimen could no longer sustain the increase in the air bag pressure, the testing was terminated.

\section{Specimen 3 (4 in. C-H Stud)}

This specimen was essentially the same as Specimen 2, except that the gypsum panels were applied in the horizontal direction. The post-test photograph of this specimen is shown in Figure 8, and a close up view of the local buckling of the $\mathrm{C}-\mathrm{H}$ stud is shown in Figure 9. The plot of the air-bag pressure vs. the panel center deflection is shown in Figure 10. The overall behavior of Specimen 3 is similar to that of Specimen 2. At about 2 psi, the compression flange of the stud began to buckle. At about 2.5 psi the buckling of the web was noted. Similar to Specimen 2, this specimen also reached a maximum pressure of about 3 psi when the panel center deflection reached about 3 inches. Removal of gypsum liner panels revealed that all studs developed buckling (See Figure 11).

\section{Summary and Discussion}

Under uniformly applied static pressure, all three test panels failed due to local buckling of the studs. Exposed two end C-H studs showed that the buckling initiated at the compression flange and propagated to the web. The 2-1/2 in stud specimen, Specimen 1, was able to resist a maximum pressure of 2 psi. Both 4 in stud specimens were able to resist a maximum pressure of 3 psi. The results of Specimen 2 and Specimen 3 indicate that the direction of application of the gypsum panels has little or no effect on the capacity of the specimen. Buckling developed in the web of the 4-in studs at a panel center deflection of the specimen about 3 in. At this point, the gypsum liner panels cracked, and both specimens were unable to sustain any further increase in pressure. The failure mode of all three tests indicates that the capacity of the panel is limited by the local buckling strength of the stud.

Although the ends of the studs were fastened to the flanges of the J-runners, the specimens behaved as simply supported rather than fixed (See the top and bottom of the failed specimens). 
The 20-gauge flanges of the J-runners did not provide sufficient stiffness to create fixed end conditions. In all three tests, the lateral movement of the J-runners was less than 0.01 in.

The span of the test specimens was $8 \mathrm{ft}-4 \mathrm{in}$. This span length is substantially less than the height of the stairway enclosure of a typical commercial building. Assuming that the height of a typical story is about $13 \mathrm{ft}$, the distance between the top of the floor to the bottom of the floor beam above would be about $11 \mathrm{ft}-4$ in after subtracting 4-in slab and 16-in steel beam. For an $11 \mathrm{ft}-4$ in. high gypsum enclosure wall section failing in the same mode as that of the $8 \mathrm{ft}-4$ in high test panel (i.e., both are failing in the local buckling of the compression flange of the stud), the following equivalent static pressure are determined based on the test results.

Table 2 Capacity of $11 \mathrm{ft}$ - 4 in high gypsum wall panel vs. Equivalent pressure of $8 \mathrm{ft}-4$ in gypsum wall panel

\begin{tabular}{|c|c|}
\hline $\begin{array}{l}\text { Capacity of } 11 \mathrm{ft}-4 \text { in high gypsum } \\
\text { system wall enclosure (psi) }\end{array}$ & $\begin{array}{l}\text { Equivalent pressure required for 8 ft-4 in } \\
\text { high gypsum system wall enclosure (psi) }\end{array}$ \\
\hline 2 & 3.70 \\
\hline 1.5 & 2.78 \\
\hline 1 & 1.85 \\
\hline
\end{tabular}

For typical commercial buildings having 13-ft story height, the tabulated values suggest that 2hour rated stairway enclosure system with 20 ga., 4 in C-H studs could resist a uniform static horizontal pressure of $1.5 \mathrm{psi}$, whereas, the same assembly with 2-1/2 in C-H studs could resist a uniform static pressure of $1.0 \mathrm{psi}$.

To resist 2 psi of horizontal static pressure on a $11 \mathrm{ft} \mathrm{-} 4$ in high wall system comprised of gypsum-stud panels having 2-hour fire rating, a $8 \mathrm{ft}$ - 4 in high wall system comprised of the same cross sectional property would require a capacity of $3.7 \mathrm{psi}$. The required capacity can be enhanced either by increasing the thickness of the $\mathrm{C}-\mathrm{H}$ stud or changing the support condition from simple to fixed support at the top and bottom of the panel. 


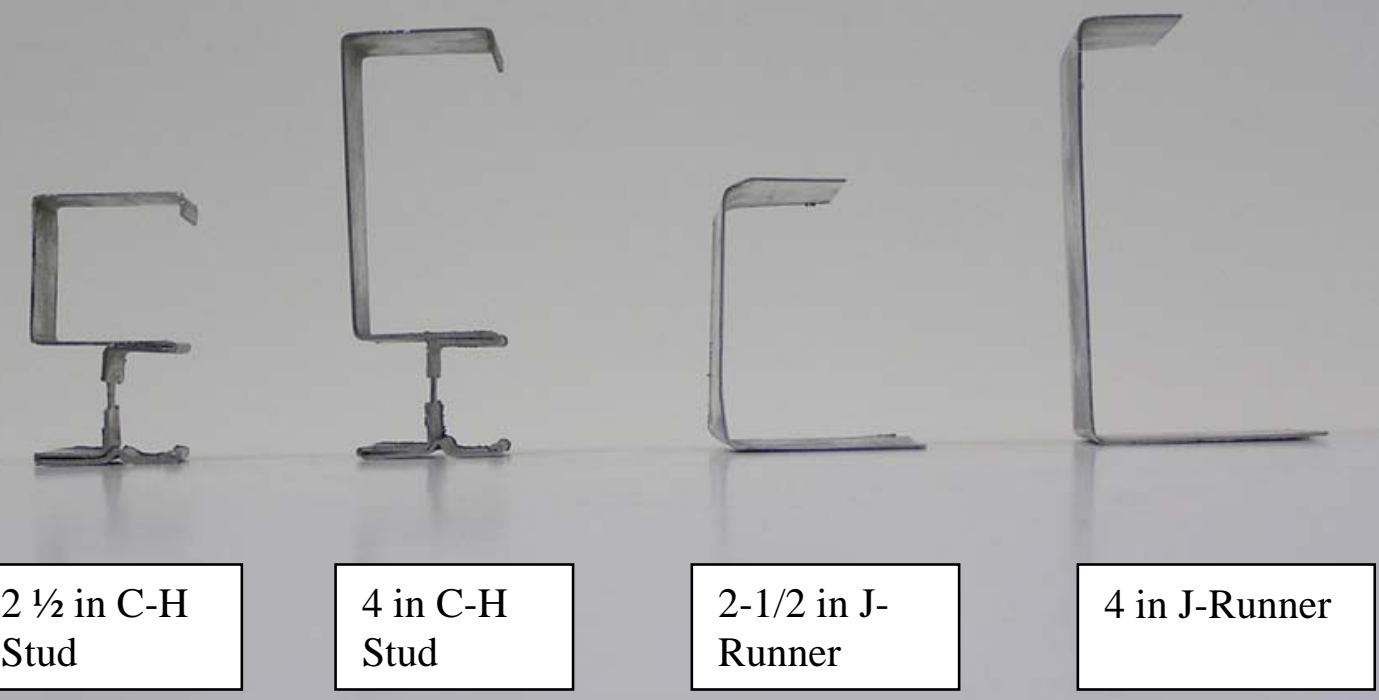

Figure 1 Cross Section of C-H Studs and J Runners 


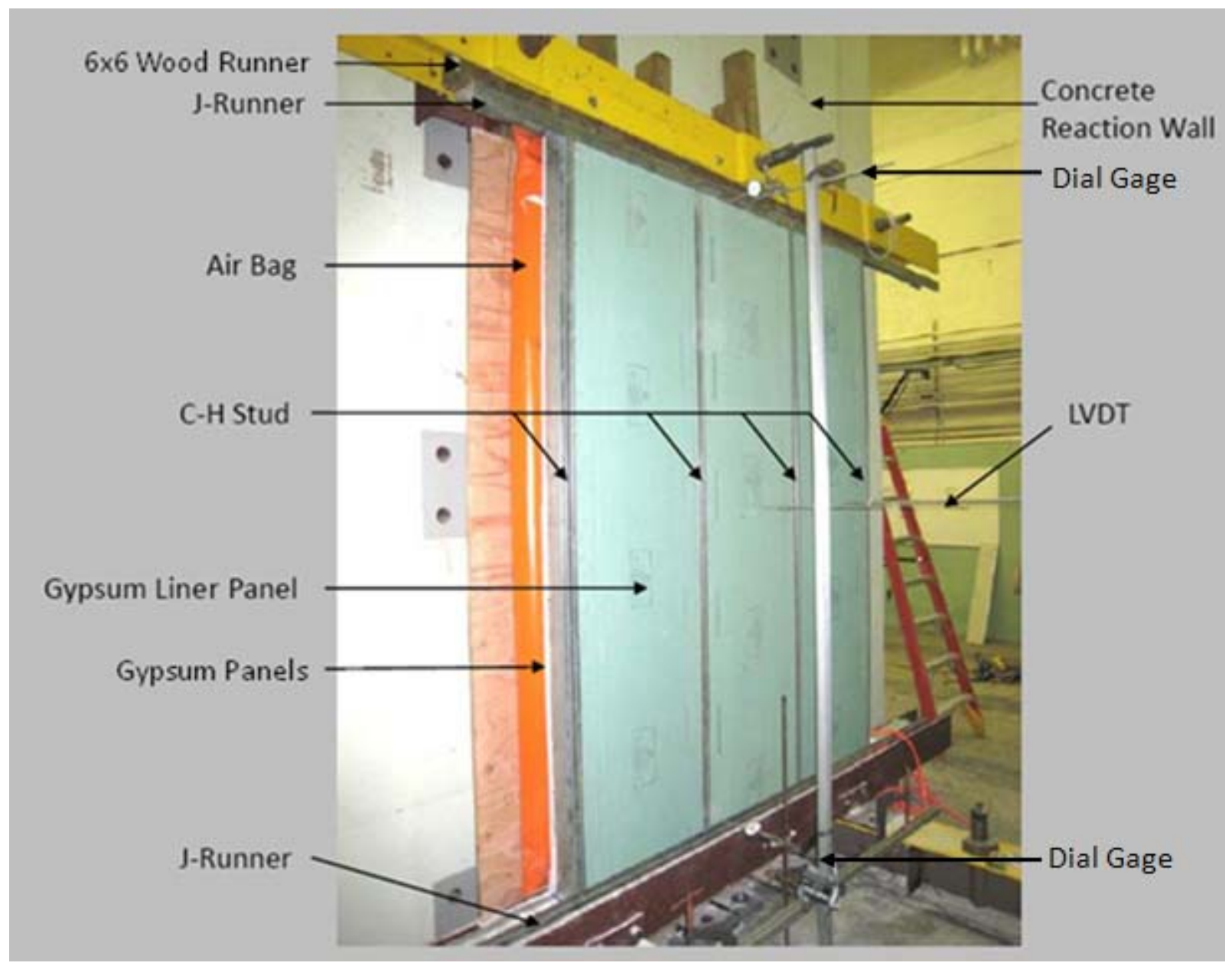

Figure 2 Test Setup 


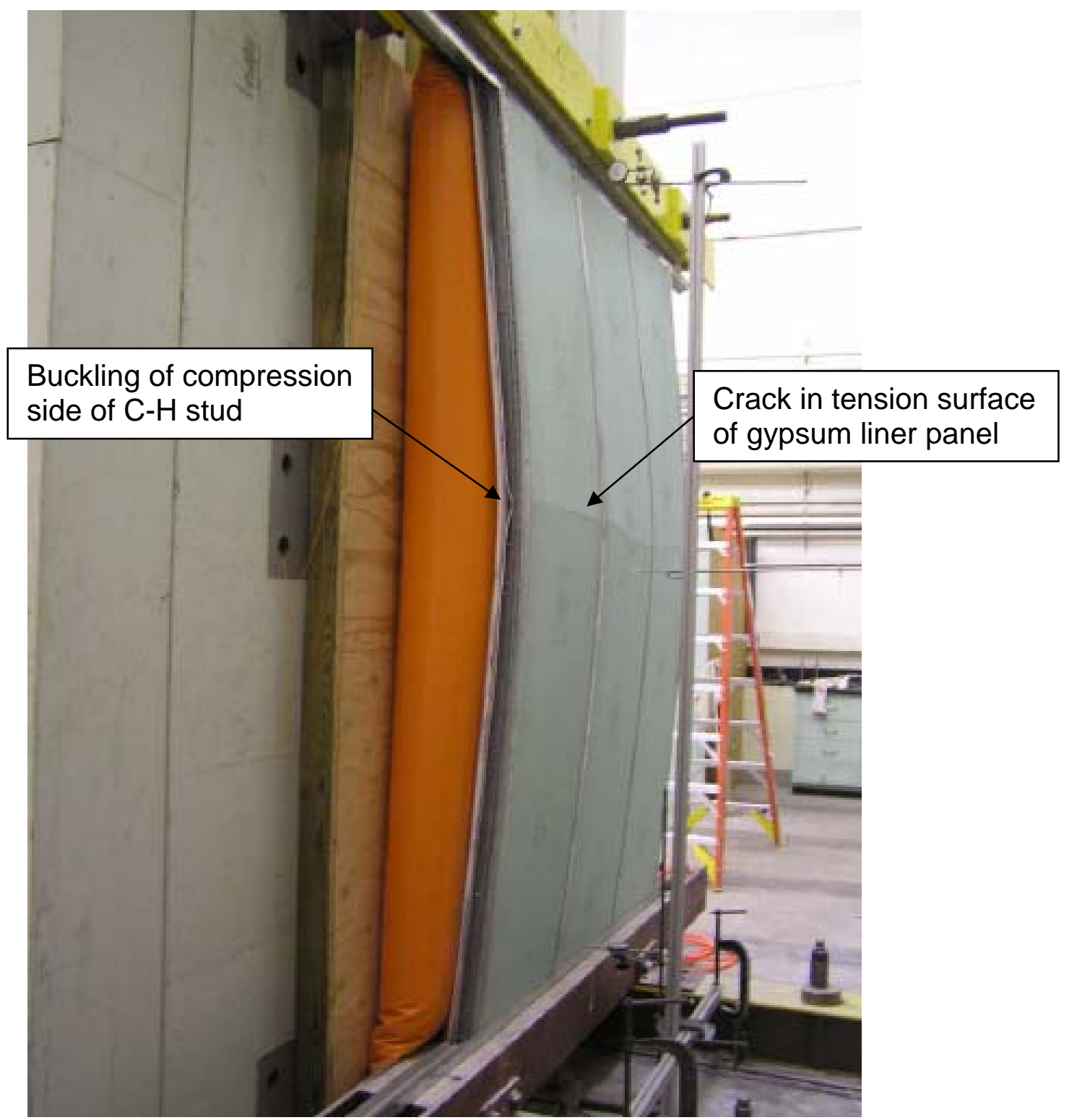

Figure 3 Post-test Photograph of Specimen 1 2-1/2 inch $\mathrm{C}-\mathrm{H}$ Stud 


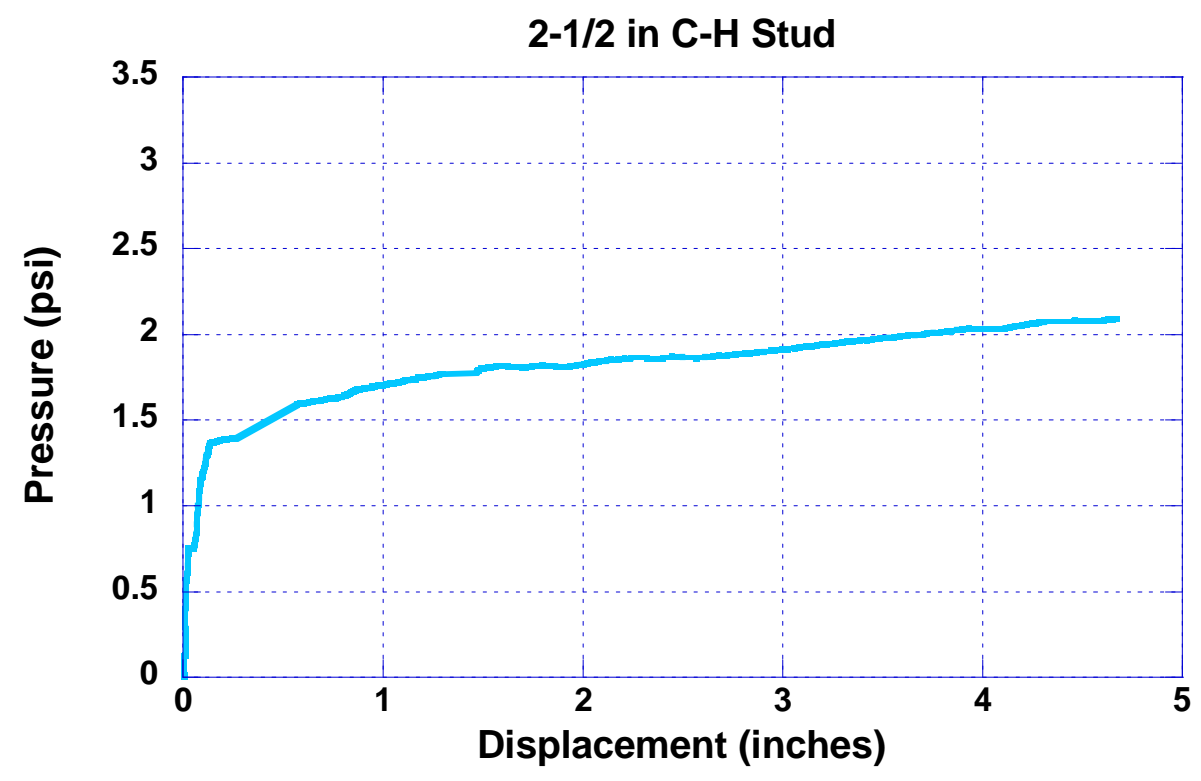

Figure 4 Air-bag pressure vs. panel center deflection plot of Specimen 1 
[Type text]

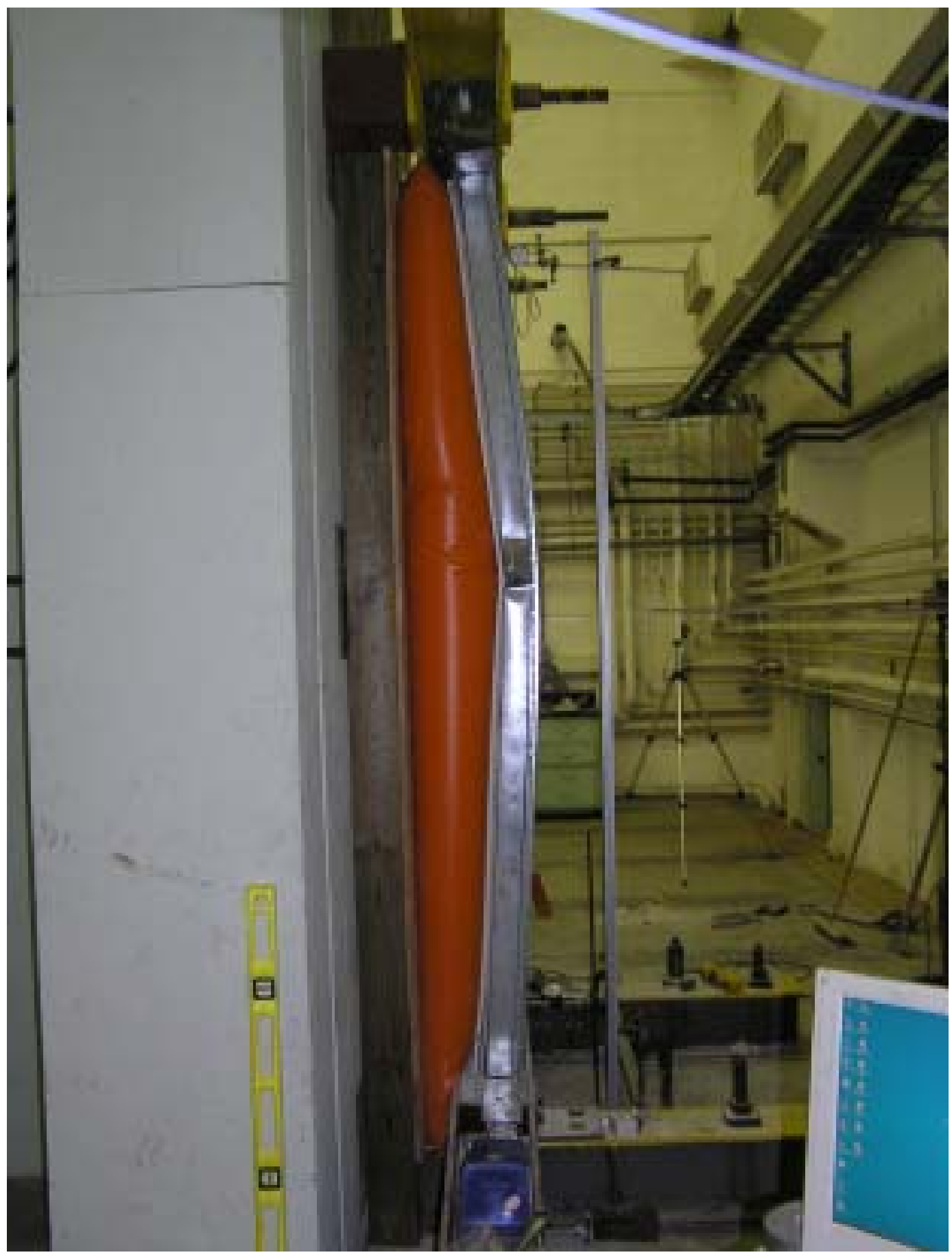

Figure 5 Post-test Photograph of Specimen 2 4 inch $\mathrm{C}-\mathrm{H}$ Stud 


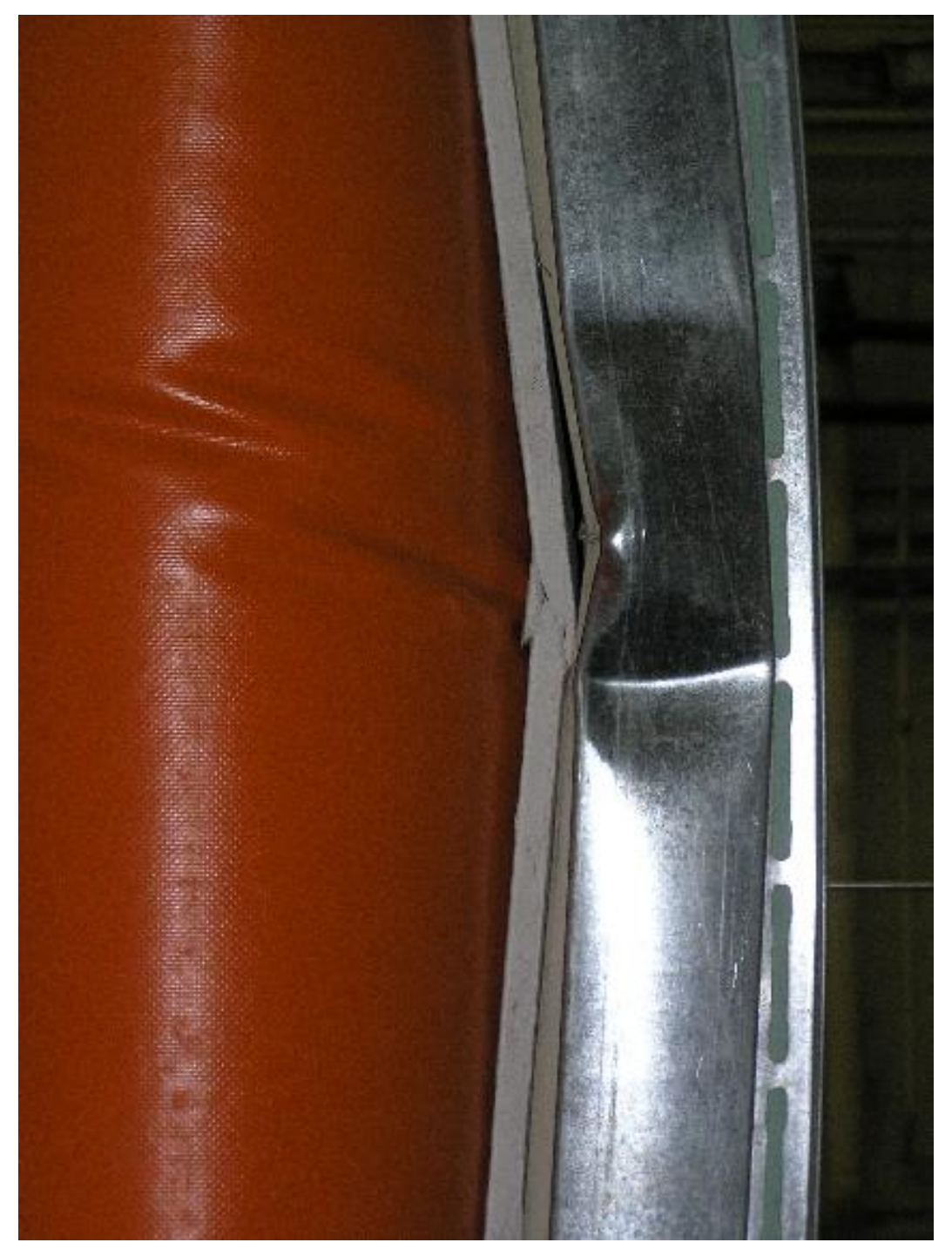

Figure 6 Close-up view of Local Buckling of $\mathrm{C}-\mathrm{H}$ Stud - Specimen 2 


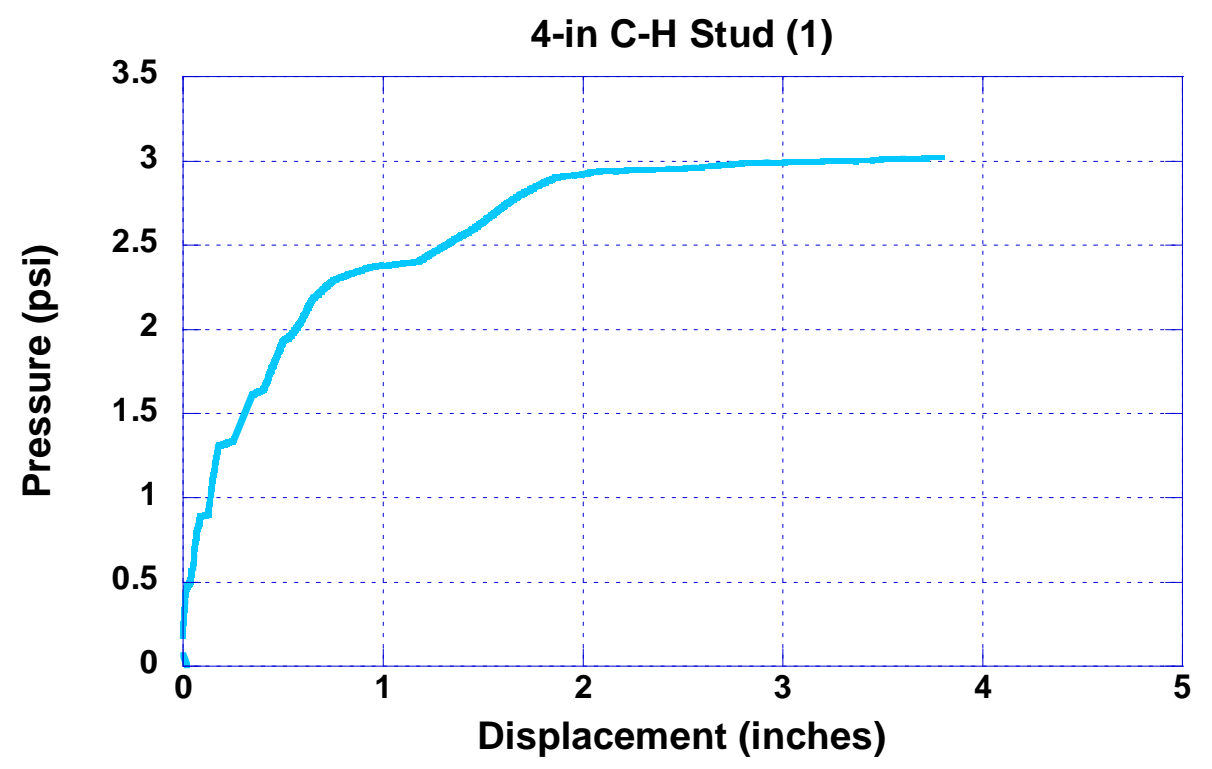

Figure 7 Air-bag pressure vs. panel center deflection plot of Specimen 2 


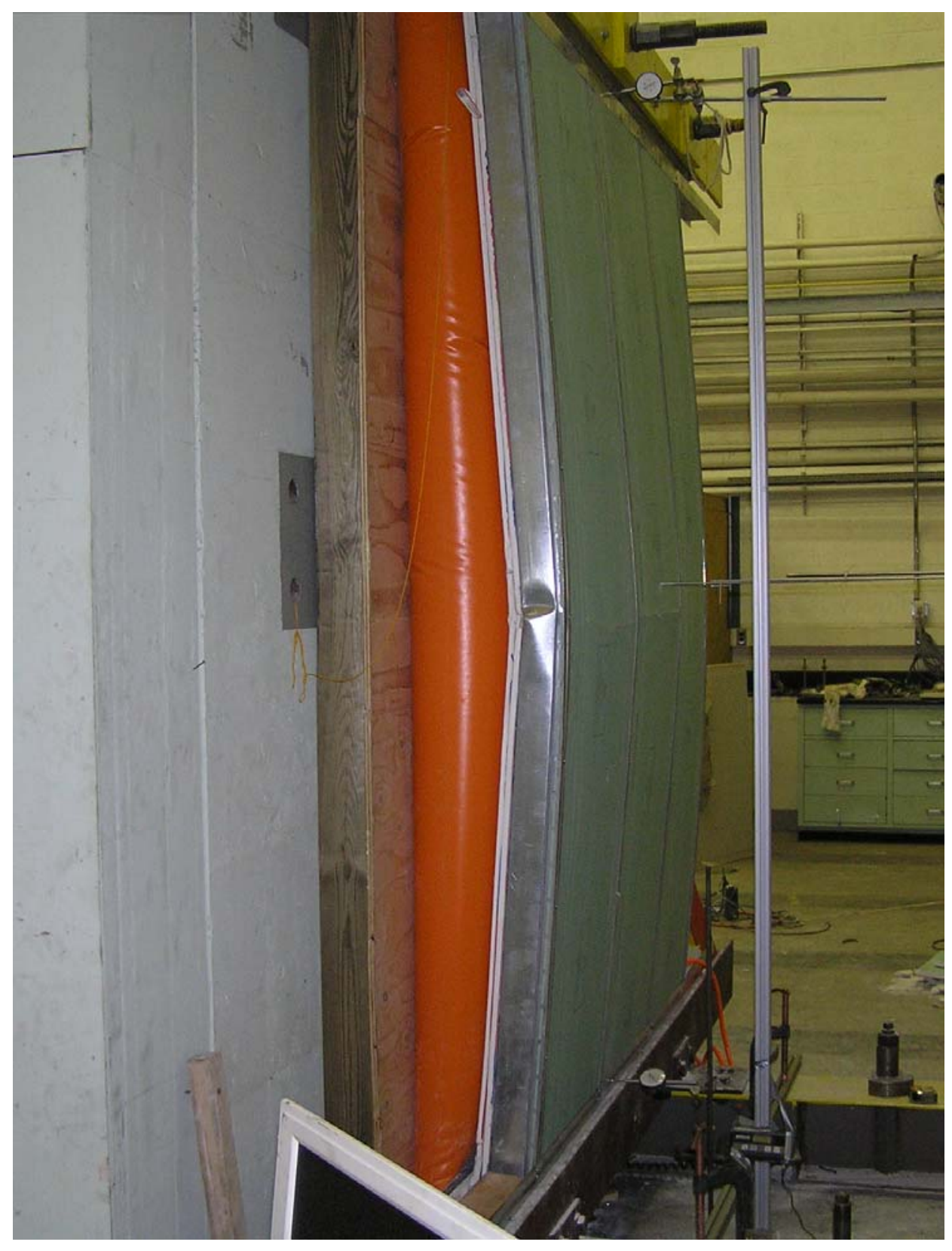

Figure 8 Post-test Photograph of Specimen 3 (4 inch C-H Stud) 
[Type text]

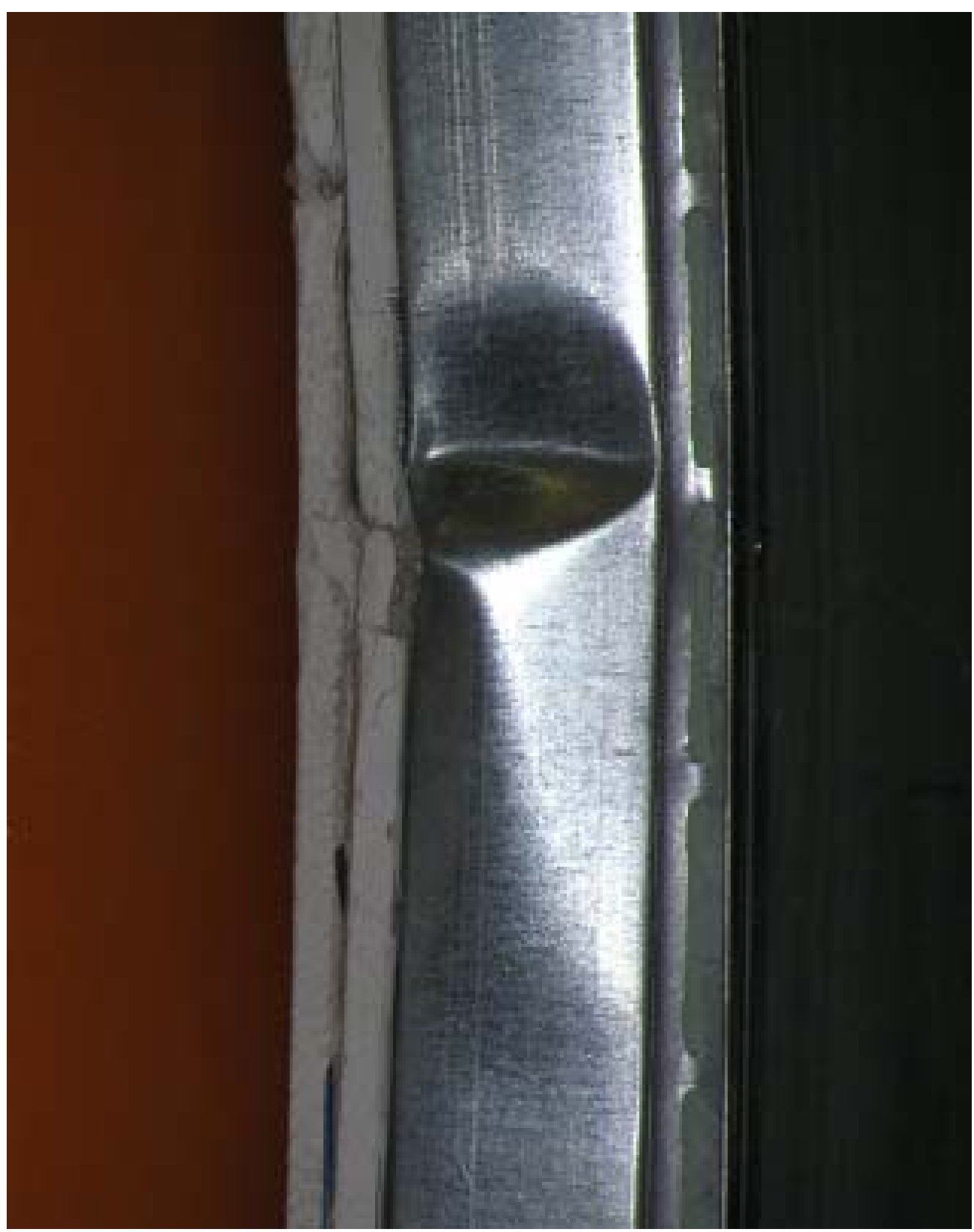

Figure 9 Close-up view of Local Buckling of C-H Stud - Specimen 3 


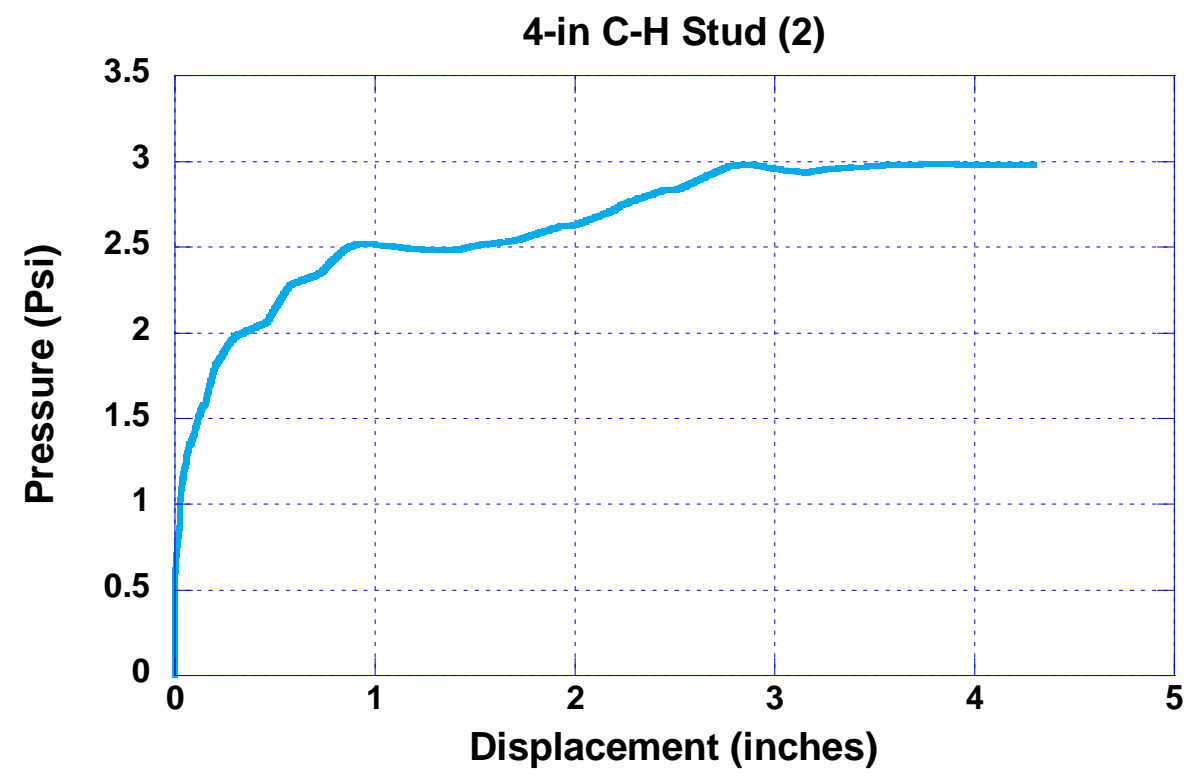

Figure 10 Air-bag pressure vs. panel center deflection plot of Specimen 3 


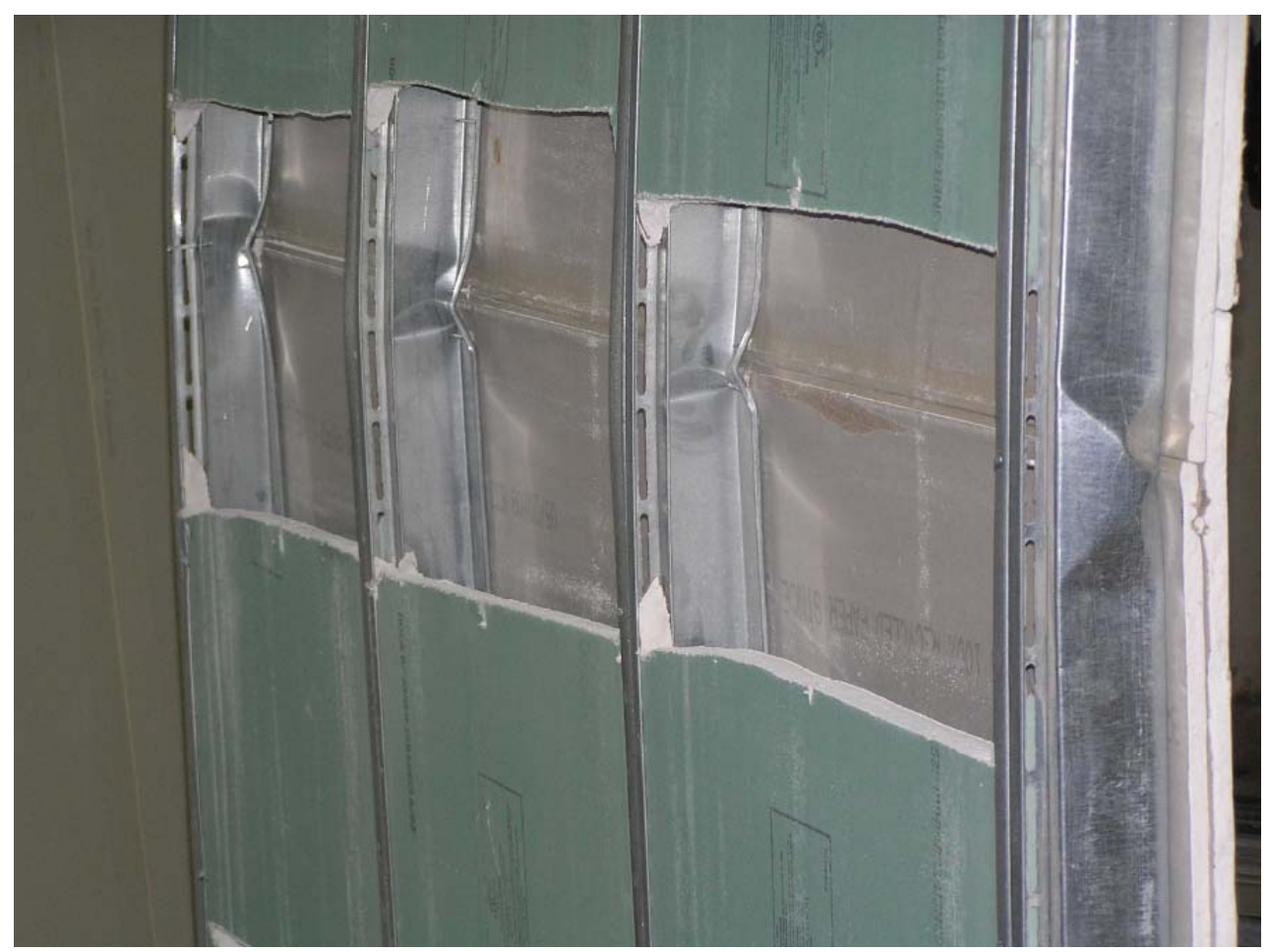

Figure 11 Development of local buckling in all four C-H studs - Specimen 3 